\title{
Metástasis adrenal única de carcinoma rectal
}

\author{
Solitary adrenal metastasis from rectal cancer
}

Francisco Javier García-Gómez ${ }^{1}$, Pablo Antonio de la Riva-Pérez ${ }^{1}$, Cristina Buján-Lloret ${ }^{1}$ y Juan Castro-Montaño ${ }^{1}$

Paciente de 67 años con antecedente de carcinoma de recto medio-superior intervenido y tratado con quimiorradioterapia hasta hace 18 meses, en estudio por masa de $10 \mathrm{~cm}$ suprarrenal derecha. En RMN abdominal (Figura 1A) no presentaba componente graso, siendo compatible con feocromocitoma o carcinoma adrenal primario y menos probable etiología metastásica. Para valorar la resecabilidad de la lesión se realizó PET/CT-18FDG (Figura 1B-C) donde presentaba áreas de necrosis central y alta actividad metabólica, sin evidencia de otras lesiones metastásicas sincrónicas. La anatomía patológica e inmunohistoquímica posadrenalectomía demostraron su naturaleza metastásica. Mediante PET/CT de control (Figura 1D-E) se confirmó la ausencia de enfermedad residual poscirugía. La presencia de una metástasis adrenal única, de origen colónico o rectal, es infrecuente para el que la adrenalectomía radical constituye el gold-standard en la actualidad ${ }^{1,2}$. En estos casos, la realización de una PET/CT juega un papel importante descartando enfermedad metastásica no sospechada a otro nivel que desaconseje el abordaje quirúrgico ${ }^{3}$.

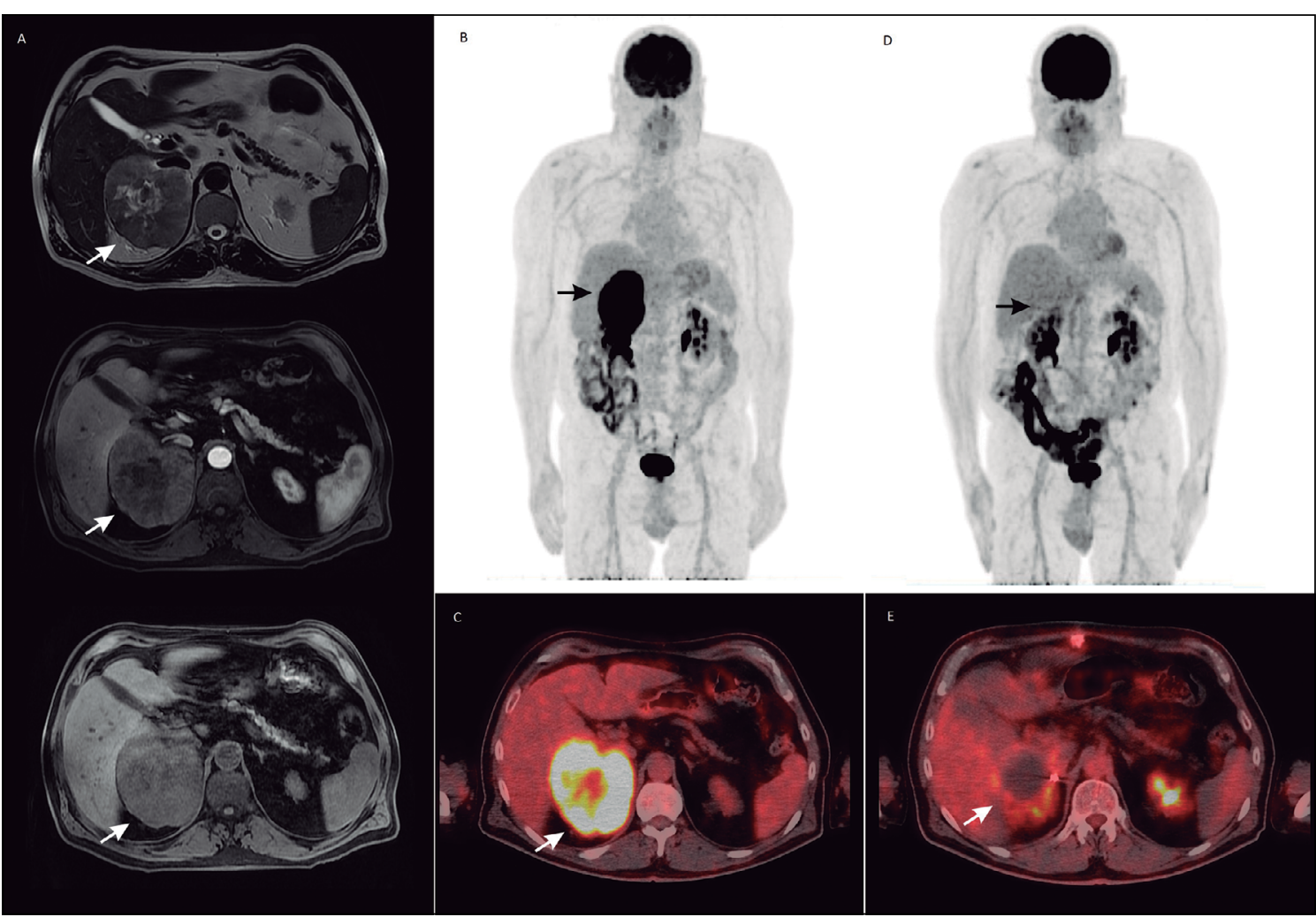

${ }^{1}$ Servicio de Medicina Nuclear. Hospital Universitario Virgen Macarena. Sevilla, España.

Recibido el 4 de mayo de 2018 y aceptado para publicación el 8 de mayo de 2018

Correspondencia a: Dr. Juan Castro-Montaño juan.castro.sspa@ juntadeandalucia.es
Figura 1. A) Secuencias RMN abdominal en que se observa masa adrenal derecha (flecha). B-C) PET/ $\mathrm{CT}$ con 18F-FDG previo a cirugía, con masa adrenal hipermetabólica sin evidencia de enfermedad metastásica a otros niveles (flecha). D-E) PET/CT con $18 F-F D G$ de control poscirugía en que se aprecia hematoma en área quirúrgica (flecha) sin hallazgos sugestivos de persistencia de enfermedad. 


\section{Responsabilidades éticas}

Protección de personas y animales. Los autores declaran que para esta investigación no se han realizado experimentos en seres humanos ni en animales.

Confidencialidad de los datos. Los autores declaran que en este artículo no aparecen datos de pacientes.

Derecho a la privacidad y consentimiento informado. Los autores declaran que en este artículo no aparecen datos de pacientes.

\section{Conflicto de intereses}

Los autores no refieren conflictos de interés.

\section{Referencias}

1. Capaldi M, Ricci G, Bertolini R, Alessandroni L, Di Castro A, Saraco E, et al. Colon cancer adrenal metastasis: case report and review of the literature. $\mathrm{G}$ Chir. 2011;32:361-3. PMID: 22018256.

2. Cantarini R, Covotta F, Aucello A, Montalto G, Procacciante F, Marcheggiani A, et al. Surgical treatment of isolated lung and adrenal metastasis from colorectal cancer. Case report. Ann Ital Chir. 2012;83:337-42. PMID: 22759471.

3. Tsuchida K, Watanabe H, Kameda Y, Uchiyama M, Asari M, Matsuura H, et al. A Case of Solitary Adrenal Metastasis from Rectal Cancer Treated by Adrenalectomy after Preoperative Chemotherapy. Gan To Kagaku Ryoho. 2016;43:1751-3. PMID: 28133120. 